\title{
Resistencia a antibióticos de última línea en cocos Gram positivos: la era posterior a la vancomicina
}

\author{
Sandra Rincón ${ }^{1}$, Diana Panesso ${ }^{1,2}$, Lorena Díaz ${ }^{1}$, Lina P. Carvajal' ${ }^{1}$, Jinnethe Reyes ${ }^{1,2}$, \\ José M. Munita ${ }^{2,3}$, César A. Arias ${ }^{1,2}$ \\ 1 Unidad de Genética y Resistencia Antimicrobiana (UGRA), Universidad El Bosque, Bogotá, D.C., Colombia. \\ 2 University of Texas Medical School at Houston, Houston, TX, USA \\ ${ }^{3}$ Clínica Alemana de Santiago, Universidad del Desarrollo, Santiago de Chile, Chile
}

En los últimos años se han desarrollado nuevas alternativas para el tratamiento de infecciones por patógenos Gram positivos multirresistentes, entre los cuales Staphylococcus aureus resistente a la meticilina (SARM) y los enterococos resistentes a la vancomicina (ERV) se consideran un verdadero reto terapéutico, y aunque el uso de la vancomicina en infecciones graves causadas por SARM ha generado serias dudas en los últimos años, continúa siendo escasa la información clínica de respaldo al uso de agentes terapéuticos que la superen en eficacia. El linezolid, la daptomicina y la tigeciclina son agentes que tienen actividad contra los cocos Gram positivos y que fueron aprobados e introducidos en la terapia clínica en la década pasada. Además, se han probado o están en las fases finales de desarrollo otros agentes como las cefalosporinas de última generación (ceftarolina y ceftobiprol).

El propósito de esta revisión fue describir las nuevas alternativas terapéuticas, particularmente en la era posterior a la vancomicina, y repasar las características químicas más relevantes de los compuestos y su espectro de actividad, haciendo énfasis en sus mecanismos de acción y resistencia.

Palabras clave: terapias complementarias, bacterias Gram positivas, farmacorresistencia microbiana, vancomicina, daptomicina, cefalosporinas.

doi: http://dx.doi.org/10.7705/biomedica.v34i0.2210

\section{Resistance to "last resort" antibiotics in Gram-positive cocci: The post-vancomycin era}

New therapeutic alternatives have been developed in the last years for the treatment of multidrugresistant Gram-positive infections. Infections caused by methicillin-resistant Staphylococcus aureus (MRSA) and vancomycin-resistant enterococci (VRE) are considered a therapeutic challenge due to failures and lack of reliable antimicrobial options. Despite concerns related to the use of vancomycin in the treatment of severe MRSA infections in specific clinical scenarios, there is a paucity of solid clinical evidence that support the use of alternative agents (when compared to vancomycin). Linezolid, daptomycin and tigecycline are antibiotics approved in the last decade and newer cephalosporins (such as ceftaroline and ceftobiprole) and novel glycopeptides (dalvavancin, telavancin and oritavancin) have reached clinical approval or are in the late stages of clinical development.

This review focuses on discussing these newer antibiotics used in the "post-vancomycin" era with emphasis on relevant chemical characteristics, spectrum of antimicrobial activity, mechanisms of action and resistance, as well as their clinical utility.

Key words: Complementary therapies, Gram-positive bacterias; drug resistance, microbial; vancomycin, daptomycin, cephalosporins.

doi: http://dx.doi.org/10.7705/biomedica.v34i0.2210

\footnotetext{
Contribución de los autores: resistencia a cefalosporinas de última generación y conclusiones.

Diana Panesso: redacción de la sección de resistencia a daptomicina.

Lorena Díaz: redacción de la sección de resistencia a las oxazolidinonas y elaboración del cuadro 1.

Lina P. Carvajal y Jinnethe Reyes: redacción de la sección de resistencia a tigeciclinas.

Jinnethe Reyes: elaboración de la figura 1.

José M. Munita: preparación, revisión y edición del manuscrito final.

Lorena Díaz y José M. Munita: preparación y revisión de la versión final del manuscrito.

Cesar A. Arias: diseño del esquema del artículo, revisión y corrección de la totalidad del manuscrito.
}

Sandra Rincón: redacción de las siguientes secciones: resumen, introducción, problemas del uso de la vancomicina en infecciones causadas por Staphylococcus aureus, la vancomicina es obsoleta en el tratamiento de infecciones por enterococos multirresistentes, 
Entre las bacterias Gram positivas, Staphylococcus aureus y Enterococcus spp. son importantes agentes etiológicos de infecciones hospitalarias y comunitarias. Estos patógenos son responsables de altas tasas de morbilidad y mortalidad en pacientes hospitalizados y generan costos elevados en las instituciones de salud de todo el mundo (1-3). Además, Enterococcus faecium y $S$. aureus hacen parte del grupo de patógenos definido por la Infectious Diseases Society of America (IDSA) como ESCAPE (E. faecium, S. aureus, Clostridium difficile, Acinetoacter baumannii, Pseudomonas aeruginosa, y Enterobacteriaceae), debido a que presentan resistencia a varios antibióticos y a que 'escapan' de la acción de la mayoría de las opciones terapéuticas disponibles (4).

\section{Problemas del uso de la vancomicina en infecciones causadas por Staphylococcus aureus}

Staphylococcus aureus es un patógeno importante que causa diversos cuadros clínicos en ambientes hospitalarios y comunitarios. Esto se debe, principalmente, a su habilidad para colonizar el huésped humano, a la presencia y expresión de importantes factores de virulencia y a su capacidad para desarrollar resistencia a varios antibióticos (5). La resistencia a la penicilina surgió en este microorganismo en 1940 debido a la adquisición de una betalactamasa codificada en plásmidos que se diseminaron rápidamente. En la actualidad, aproximadamente $90 \%$ de los aislamientos clínicos de $S$. aureus es resistente a este antibiótico (5). La resistencia a la meticilina $(S$. aureus resistente a la meticilina, SARM), reportada inicialmente en 1961 y mediada por la adquisición del gen mecA de origen cromosómico, también se diseminó rápidamente en los hospitales del mundo y hoy ha alcanzado proporciones epidémicas en algunos países, lo que, junto a la reciente aparición de clones de SARM adquiridos en la comunidad (SARM-AC), ha tenido un impacto importante en los sistemas de salud (5-7).

Es por esta razón que la vancomicina, un glucopéptido que inhibe la síntesis de la pared celular por medio de la unión a la terminación D-Ala-D-Ala del peptidoglucano, ha sido el antibiótico de primera

Correspondencia:

César A. Arias, University of Texas Medical School, 6431 Fannin St., Room 2.112 MSB, Houston, Texas 77030, USA

Teléfono: (713) 500 6738; fax: (713) 5005495

cesar.arias@uth.tmc.edu

Recibido: 27/11/13; aceptado: 31/01/14 línea en el tratamiento de infecciones graves causadas por SARM durante más de cuatro décadas (8). Sin embargo, tres problemas relacionados con este antibiótico causan preocupación y se han convertido en objeto de diversas investigaciones a nivel mundial: i) la emergencia de cepas de estafilococo con sensibilidad disminuida a la vancomicina; ii) los reportes sobre el fracaso del tratamiento de infecciones causadas por aislamientos sensibles con concentraciones inhibitorias mínimas (CIM) cercanas al punto de corte establecido para este antibiótico $(2 \mu \mathrm{g} / \mathrm{ml})$ (4), y iii) su asociación con efectos secundarios, particularmente en lo relacionado con la insuficiencia renal aguda (9-12).

En cuanto a la disminución de la sensibilidad, el Clinical Laboratory Standards Institute (CLSI) define como sensibles a los aislamientos de $S$. aureus con una CIM para vancomicina de $\leq 2 \mu \mathrm{g} / \mathrm{ml}$ y como no sensibles a los aislamientos que presentan una CIM de $\geq 2 \mu \mathrm{g} / \mathrm{ml}$. Los aislamientos con una CIM de entre 4 y $8 \mu \mathrm{g} / \mathrm{ml}$ se consideran como de sensibilidad intermedia a la vancomicina y aquellos con una CIM $\geq 16 \mu \mathrm{g} / \mathrm{ml}$, como resistentes (13).

Los aislamientos con sensibilidad intermedia a la vancomicina comenzaron a reportarse en la década de los 90 , siendo el primero de ellos una cepa denominada Mu50, recuperada en Japón de una muestra proveniente de la herida quirúrgica de un paciente pediátrico que no respondió al tratamiento con la vancomicina (14).

Por otra parte, entre las cepas sensibles ( $\mathrm{CIM} \leq 2 \mu \mathrm{g} /$ $\mathrm{ml}$ ) existe un grupo que exhibe la así denominada heterorresistencia a la vancomicina y que es difícil de identificar, ya que la resistencia se observa en subpoblaciones cuya CIM alcanza valores de entre 4 y $8 \mu \mathrm{g} / \mathrm{ml}$ (15). El primero de estos aislamientos (Mu3) fue recuperado de una muestra de esputo en un paciente de 64 años con neumonía que no respondió al tratamiento con vancomicina y que presentaba una subpoblación celular con una CIM intermedia a vancomicina (frecuencia $<10^{-5}-10^{-6}$ ) (16). Como se mencionó anteriormente, la detección de la heterorresistencia a vancomicina es particularmente exigente, pues solo se logra con certeza mediante análisis complicados que identifican subpoblaciones bacterianas. Las técnicas para detectar estas subpoblaciones son demasiado complejas para utilizarlas de manera rutinaria e, infortunadamente, no existen herramientas de tamización suficientemente confiables para usarlas en el laboratorio clínico. Las infecciones causadas por $S$. aureus de sensibilidad 
intermedia o con heterorresistencia a la vancomicina se asocian a una mayor frecuencia de fracaso terapéutico con este medicamento y a un mayor número de episodios de bacteriemia prolongada o persistente $(17,18)$. Varias series clínicas (en la mayoría retrospectivas) han sugerido que el uso de la vancomicina para el manejo de infecciones graves causadas por SARM con una CIM de $2 \mu \mathrm{g} / \mathrm{ml}$ lleva al fracaso del tratamiento (12).

Entre los principales factores de riesgo para la infección por $S$. aureus de sensibilidad intermedia o con heterorresistencia a la vancomicina se encuentran el antecedente de infección o colonización por SARM, la exposición a la vancomicina y algunas enfermedades concomitantes como la diabetes y la insuficiencia renal (17-19).

El mecanismo de resistencia en las cepas de $S$. aureus de sensibilidad intermedia o con heterorresistencia a la vancomicina no involucra la adquisición de genes típicos de resistencia a la vancomicina (genes van), sino una alteración adaptativa de la fisiología celular debida a la acumulación de mutaciones en diversos genes (cuadro 1), lo que resulta en cambios importantes de la homeostasis de la síntesis de la pared bacteriana y en una disminución de la actividad autocatalítica $(15,20)$. Como consecuencia, uno de los fenómenos comúnmente observado es el incremento en el grosor de la pared bacteriana (el cual aumenta casi al doble). Se postula que este engrosamiento contribuye a 'atrapar' el antibiótico (por ejemplo, la vancomicina) en las capas más externas de peptidoglucano (figura 1A), evitando su interacción con los precursores del peptidoglucano que emergen del citoplasma y permitiendo una síntesis activa de la pared celular en presencia del antibiótico $(21,22)$.

Preocupa mucho más el hallazgo reciente de los primeros casos de $S$. aureus resistente a la vancomicina (SARV) por la adquisición del grupo de genes vanA 'donados' por cepas de enterococos resistentes a la vancomicina $(23,24)$. A la fecha, se han publicado reportes de 15 casos de SARV, la mayoría en los Estados Unidos con 11 casos, dos en India, uno en Irán, y otro recientemente en Brasil (25-28) (Rossi F, Díaz L, Wollan A, Panesso D, Zhou Y, Rincón S, et al. Transferable high-level vancomycin resistance in community-associated MRSA lineage. $\mathrm{N}$ Engl J Med. En prensa). La adquisición de los genes vanA se debe, por lo general, a la transferencia de elementos genéticos móviles (transposón Tn 1546) usualmente presentes en los plásmidos de conjugación (29).
En cuanto a las características epidemiológicas y moleculares de las infecciones por SARV, los 11 casos iniciales encontrados en los Estados Unidos comprometen cepas recuperadas de infecciones de la piel y tejidos blandos o de colonizaciones y se agrupan dentro del linaje genético de cepas hospitalarias conocido como complejo 'clonal' 5 (CC5) $(30,31)$. A diferencia de estos, el caso recientemente descrito en Brasil correspondía a una cepa de SARV recuperada de una muestra de sangre y clasificada dentro del linaje de cepas comunitarias, más específicamente el clon USA300ST8 del CC8, el cual se asocia a infecciones graves y se ha convertido en el clon epidémico de SARMAC predominante en el mundo (Rossi F, Díaz L, Wollan A, Panesso D, Zhou Y, Rincón S, et al. Transferable high-level vancomycin resistance in community-associated MRSA lineage. N Engl J Med. En prensa).

Por último, el uso de dosis altas de vancomicina con base en los parámetros de la dinámica farmacológica ha puesto en cuestión el perfil de seguridad de este antibiótico. De hecho, algunos trabajos sugieren que el uso de esquemas agresivos de dosificación está correlacionado con una probabilidad alta de riesgo nefrotóxico.

\section{La vancomicina es obsoleta en el tratamiento de infecciones por enterococos multirresistentes.}

Los enterococos son importantes agentes causantes de infecciones hospitalarias que afectan principalmente a pacientes inmunosuprimidos e intervenidos con catéteres intravasculares en unidades de cuidados intensivos y a aquellos que reciben múltiples esquemas de antibióticos. Estos microorganismos generalmente se consideran de baja capacidad patógena, sin embargo, presentan una alta capacidad adaptativa dada la plasticidad de su genoma, la resistencia intrínseca a varios antibióticos y la gran habilidad de adquirir y diseminar genes de resistencia $(32,33)$.

Entre dichos microorganismos, uno de los hallazgos más relevantes ha sido el de los enterococos resistentes a la vancomicina. Estas cepas fueron descritas 15 años después de la introducción de la vancomicina en la práctica clínica. Su mecanismo de resistencia se debe a la adquisición de los genes van, responsables de la síntesis de precursores modificados de peptidoglucano, lo que disminuye la afinidad de la vancomicina. Si bien se han descrito muchos tipos de grupos de genes van, los dos fenotipos más frecuentes son el VanA (que produce resistencia a vancomicina y teicoplanina), 


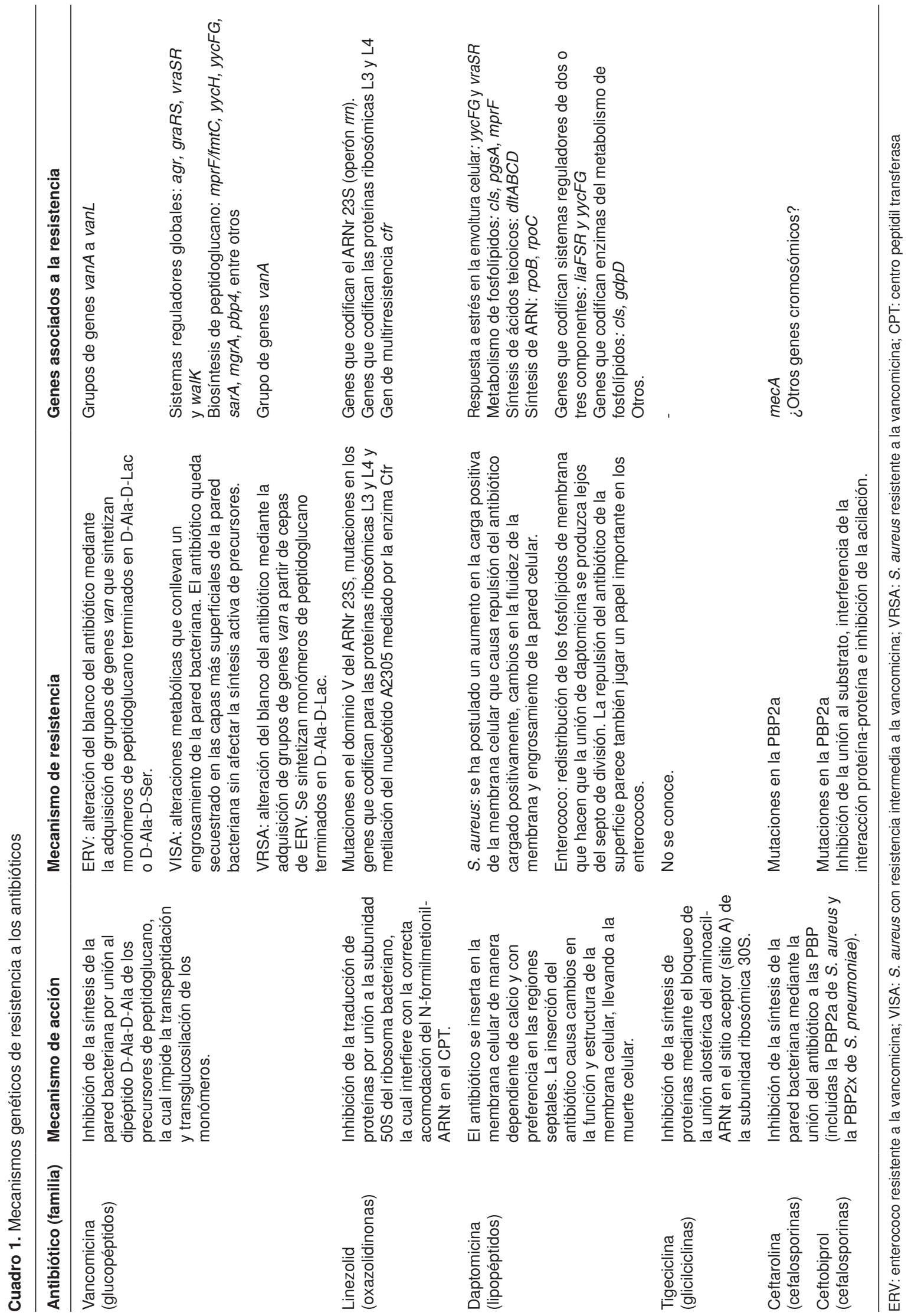


A. S. aureus
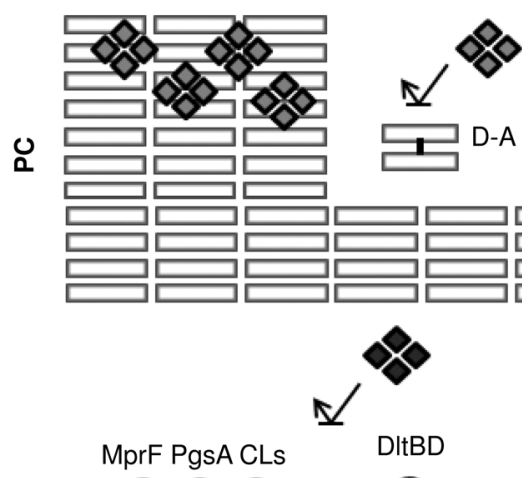

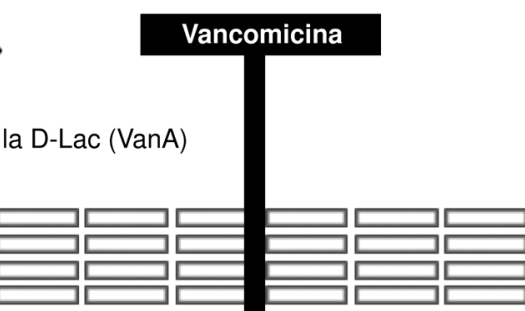

Vancomicina

.

Daptomicina

ט
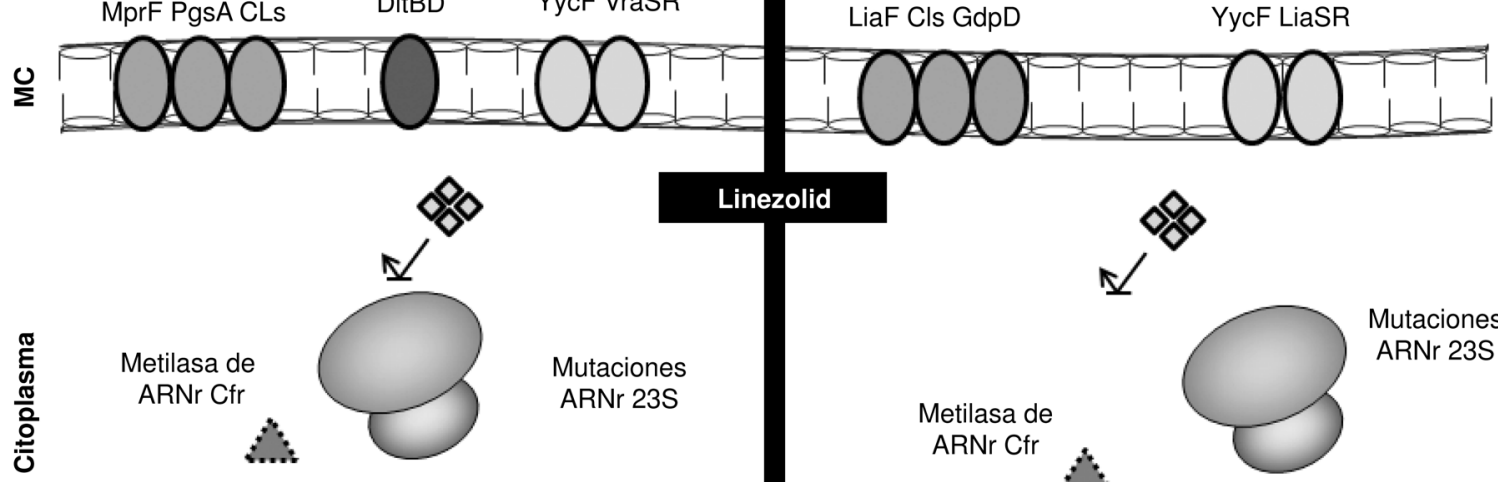

Cambios en proteínas ribosomales L3 y L4
B. Enterococos

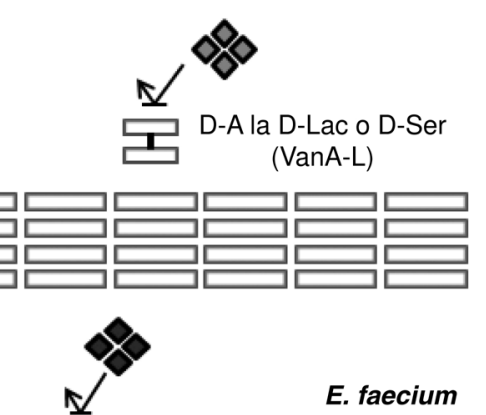

E. faecium
E. faecalis

.


frecuencia la secuencia de inserción IS16 y el gen de resistencia a ampicilina $p b p 5 R$, así como islas de capacidad patógena, plásmidos o genes asociados con resistencia a antibióticos, colonización y virulencia (35). Además, algunos hallazgos genómicos indican que el clado hospitalario cobró fuerza hace, aproximadamente, 75 años (simultáneamente con el desarrollo de los antibióticos) a partir de una población que incluía cepas provenientes de animales (36). También se encontró que el linaje en el cual se encontraba la mayoría de cepas de origen animal se separó del linaje de cepas comensales humanas hace 3.000 años. Estas separaciones se produjeron conjuntamente con la adquisición de nuevas habilidades metabólicas y de colonización, así como de elementos móviles que generaban variaciones en los genomas (36).

Frente a este panorama, el tratamiento de infecciones producidas por cocos Gram positivos multirresistentes constituye un reto clínico enorme (2), ya que los antibióticos de uso común han perdido su efectividad $y$, a pesar de la disponibilidad de nuevos agentes, estos patógenos continúan adaptándose y desarrollando nuevos mecanismos de resistencia (37-39).

En esta revisión discutimos las características más relevantes de los nuevos agentes disponibles para el tratamiento de infecciones causadas por enterococos y $S$. aureus, haciendo énfasis en sus mecanismos moleculares de acción y de resistencia.

\section{Resistencia a oxazolidinonas}

El linezolid es un antibiótico sintético y el primer miembro de la familia de las oxazolidinonas, el cual fue introducido en la práctica clínica en los Estados Unidos en el año 2000 (40). Está indicado para el tratamiento de infecciones complicadas de la piel y de neumonías causadas por bacterias Gram positivas, incluidos los enterococos, los estreptococos y SARM; además, está aprobado para el tratamiento de infecciones por $E$. faecium resistente a la vancomicina (41).

El linezolid es un agente bacteriostático que inhibe la síntesis proteica mediante la unión a la subunidad $50 S$ del ribosoma bacteriano interfiriendo con la correcta acomodación del N-formil-metionil-ARN de transferencia (ARNt) en el centro peptidiltransferasa (CPT) (42). La unión con la subunidad $50 S$ se da por interacción con el ARN ribosómico (ARNr) 23S, más específicamente con ocho nucleótidos universalmente conservados (G2061,
A2451, C2452, A2503, U2504, G2505, U2506 y U2585 [numeración del ribosoma de Escherichia coli]) y con las proteínas ribosómicas que se encuentran más próximas a su sitio de unión, es decir, las L3, L4 y L22. Esta unión causa rigidez en el nucleótido U2585, el cual normalmente presenta una flexibilidad molecular que es crucial para el posicionamiento correcto del ARNt en el sitio P del CPT y, como consecuencia, el antibiótico produce una interrupción temprana de la síntesis de péptidos (42).

A pesar de que la resistencia a linezolid se viene reportando desde el 2001 (43), su frecuencia continúa siendo baja entre las bacterias Gram positivas (inferior a 0,5\%) (44-48). La resistencia al linezolid se explica por tres mecanismos que alteran el blanco del antibiótico afectando su unión al ribosoma (figura 1, cuadro 1): i) las mutaciones en el dominio $\mathrm{V}$ del ARNr 23S (43); ii) las mutaciones en los genes que codifican para las proteínas ribosómicas L3 y L4 $(49,50)$, y iii) la metilación del nucleótido A2305 por parte de la enzima denominada Cfr (Chloramphenicol Florfenicol Resistance) (51).

Entre estos mecanismos, el principal es el de las mutaciones en el dominio $\mathrm{V}$ del ARNr 23S, siendo la mutación G2576U la más frecuentemente reportada (52). Estas mutaciones pueden presentarse en una, algunas o todas las copias de los genes que codifican el ARNr bacteriano y se ha observado una correlación directa entre el número de copias mutadas y el nivel de resistencia al linezolid (53). Cabe destacar que las mutaciones en los genes que codifican para los ARNr parecen afectar la viabilidad bacteriana (bacterial fitness), observándose una relación inversa entre el número de copias mutadas y la capacidad de crecimiento de la bacteria (53). La aparición de este mecanismo de resistencia in vivo se ha asociado con prolongados esquemas de tratamiento con linezolid y con su amplio uso en instituciones hospitalarias $(54,55)$.

Como ya se mencionó anteriormente, los cambios en los genes que codifican las proteínas ribosómicas L3 y L4 también se han asociado con la resistencia al linezolid. Es más, cuando estas mutaciones se dan simultáneamente con otros mecanismos de resistencia, presentan un efecto sinérgico, incrementando aún más el nivel de resistencia. En estafilococos resistentes a linezolid, la mayoría de cambios en los aminoácidos se han reportado en la proteína ribosómica L3 $(49,50)$. El tercer mecanismo, que es el único transferible, se debe a 
la metilación en el carbono 8 del nucleótido A2503 del ARNr 23S por medio de la enzima denominada Cfr, codificada por el gen cfr, el cual generalmente está asociado a elementos genéticos móviles como los plásmidos y los transposones. Este mecanismo afecta la actividad de seis familias de antibióticos, incluidas las de fenicoles, lincosamidas, oxazolidinonas, pleuromutilinas, estreptograminas A y los macrólidos josamicina y espiramicina, por lo que se ha acuñado la sigla PhLOPSA (Phenicols, Lincosamides, Oxazolidinones, Pleuromutilins y Streptogramins A) para referirse al fenotipo de múltiple resistencia a estos antibióticos.

El gen cfr fue reportado inicialmente en aislamientos de estafilococos de origen animal que conferían resistencia a los fenicoles, y su primera descripción se realizó en el 2000 en Alemania durante una actividad de vigilancia de la resistencia a florfenicol; en esa ocasión se recuperó un aislamiento de Staphylococcus sciuri proveniente de un hisopado nasal de un ternero que portaba el gen cfr en un plásmido $(17,1 \mathrm{~kb})$ denominado pSCFS1 $(56,57)$. Dicho plásmido portaba, igualmente, el gen de resistencia erm(33), el cual codifica otra metilasa que confiere resistencia a macrólidos, lincosamidas y estreptograminas $B, y$ los genes isa y $s p c$, que confieren resistencia a lincosamidas y espectinomicina, respectivamente. Posteriormente, el cfr fue descrito en una cepa de $S$. aureus de origen porcino, en un plásmido denominado pSCFS3 (36 kb) que, además, presentaba el gen fexA asociado con resistencia a fenicoles $(58,59)$.

El primer aislamiento de estafilococos de origen humano portador del gen cfr se describió en un aislamiento de SARM recuperado en un paciente con neumonía asociada al respirador en Medellín $(51,60)$. Es relevante anotar que este aislamiento de SARM portaba el gen cfr en el cromosoma y no en los plásmidos, como se describió inicialmente en cepas de animales, y estaba asociado con elementos transponibles y con el gen de resistencia ermB (58). El análisis de transcripción mostró que el cfr se expresaba conjuntamente con el gen ermB como parte de la unidad genética denominada $\mathrm{m} / \mathrm{r}$ (modification of large ribosomal subunit) (61). Posteriormente se publicaron dos reportes de aislamientos de estafilococos resistentes al linezolid portadores del cfr en Estados Unidos, en S. aureus (004-737X) y en Staphylococcus epidermidis (426-3147L), que presentaron una CIM para linezolid de 8 y $>256 \mu \mathrm{g} /$ $\mathrm{ml}$, respectivamente (62). En el aislamiento de $S$. aureus 004-737X, el cfr se localizó en un plásmido con un ambiente genético idéntico al previamente descrito en el pSCFS3 de S. sciuri. Después, en el 2008, se reportó un brote de infecciones causadas por $S$. aureus resistentes a linezolid en un hospital de Madrid, España, que afectó a 15 pacientes, de los cuales, 12 se encontraban en la unidad de cuidados intensivos (63); en esa ocasión el gen cfr se encontró en todos los aislamientos, algunos de los cuales presentaban, además, mutaciones en la proteína ribosómica L3 (64). El cfr también ha sido reportado en aislamientos clínicos de estafilococo resistente a linezolid en Italia (50) y México (65), $y$, recientemente, se aisló en Irlanda $S$. aureus con características de SARM-AC (positivo para PVL, SCCmeclVa y ST8), el cual presentó resistencia a linezolid mediada por el gen cfr localizado en un plásmido de conjugación (66).

En el 2011 se reportó en China la presencia del gen cfr en E. faecalis (67) recuperado de heces de bovinos y de Bacillus spp. proveniente de heces de cerdos $(68,69)$. El primer reporte de una cepa de enterococo portadora del gen cfr en humanos fue en $E$. faecalis, la cual se recuperó en un paciente tailandés (70). Más recientemente se reportó en Canadá una cepa clínica de E. faecium portador de este mecanismo de resistencia (71). Lo anterior demuestra la capacidad del cfr para transferirse de animales a especies y géneros bacterianos que son importantes patógenos humanos. Aunque algunos estudios in vitro sugieren que el cfr no causa impacto en el crecimiento bacteriano (72), los estudios in vivo demuestran que su impacto en la resistencia es menor al mediado por el mecanismo de mutación y puede ser contrarrestado con altas dosis del antibiótico (73). Es importante anotar que en los últimos años se han desarrollado nuevas moléculas de oxazolidinonas con espectro extendido (por ejemplo, torezolid y tedizolid) que muestran una importante actividad contra cepas resistentes a linezolid que poseen tanto el mecanismo de mutación como el mediado por el cfr (74).

\section{Resistencia a la daptomicina}

La daptomicina es un lipopéptido cíclico producido por Streptomyces roseosporus (75), el cual presenta una estructura cíclica y una cadena lateral lipofílica compuesta por un ácido decanoico (76). Este antibiótico tiene actividad contra un amplio grupo de organismos Gram positivos y presenta una gran capacidad bactericida in vitro contra SARM y contra enterococos resistentes a la vancomicina. Su uso está aprobado por la Food and Drug 
Administration (FDA) para el tratamiento de infecciones de la piel y de los tejidos blandos, de la bacteriemia y de la endocarditis derecha causadas por $S$. aureus sensible a la meticilina. A pesar de no estar aprobada para las infecciones causadas por enterococos resistentes a la vancomicina, la carencia de opciones terapéuticas hace que su uso para el manejo de estos cuadros sea una práctica habitual (77).

La actividad de la daptomicina depende de la unión a cationes de calcio cargados positivamente que actúan como un péptido catiónico antimicrobiano $(78,79)$, de forma similar a los producidos por células del sistema inmune innato (por ejemplo, los neutrófilos). La interacción del complejo daptomicinacalcio con la membrana celular bacteriana, cuya carga es usualmente negativa debido a los grupos fosfato en los fosfolípidos, genera una perturbación fisiológica y estructural que lleva a la muerte celular $(80,81)$. Esta interacción no está del todo clara, sin embargo, algunos estudios recientes indican que la daptomicina se 'oligomeriza' dentro de la membrana celular en una reacción dependiente del fosfatidilglicerol y causa daños en su ultraestructura (82). Utilizando un modelo de Bacillus subtilis, Pogliano, et al., propusieron que la daptomicina se inserta en la membrana celular con preferencia por el septo bacteriano, que es el lugar donde ocurre la división celular y, de esta forma causa alteraciones en la membrana, la división celular y la formación del peptidoglucano (83).

\section{Resistencia a la daptomicina en Staphylococcus aureus}

La resistencia a la daptomicina en $S$. aureus ha sido ampliamente descrita (84-87), sin embargo, su prevalencia continúa siendo baja. Es así como en un estudio de vigilancia epidemiológica en el que se evaluaron 10.000 aislamientos clínicos de $S$. aureus en los Estados Unidos se detectó una prevalencia de resistencia a la daptomicina de $0,4 \%$ (88). Por otra parte, un estudio en hospitales de Europa, Latinoamérica, Australia, Nueva Zelandia e India demostró que más de $99 \%$ de las cepas estudiadas era sensible a la daptomicina (89). El mecanismo de resistencia aún no está totalmente esclarecido, pero existen varias teorías, destacándose la hipótesis que postula que la bacteria adapta la superficie celular para mantener una carga más positiva con el fin de 'repeler' eléctricamente el complejo daptomicina-calcio (90). No obstante, se han reportado aislamientos resistentes a la daptomicina sin cambios en la carga de la superficie celular, lo que sugiere que existen vías alternas para el desarrollo de la resistencia (91). En lo concerniente a las bases genéticas, los grupos de genes implicados en la resistencia a la daptomicina en $S$. aureus incluyen los siguientes: i) genes relacionados con alteraciones en la carga de la membrana; ii) genes que codifican sistemas reguladores que orquestan la respuesta al estrés de la envoltura celular, y iii) genes que regulan el metabolismo de los fosfolípidos (figura 1A, cuadro 1).

Con respecto al primer grupo, uno de los principales genes descritos es el mprF, el cual codifica para una sintetasa de lisil-fosfatidilglicerol (MprF) (92). Esta es una enzima bifuncional que se encarga de la adición de lisina (aminoácido de carga positiva) a residuos de fosfatidilglicerol en la capa interna de la membrana celular, formando lisilfosfatidilglicerol (L-FG), y de la translocación de L-FG desde la capa interna hacia la capa externa de la membrana (actividad de flipasa) (93-95). En cepas de $S$. aureus resistentes a la daptomicina se han descrito diversas mutaciones en el mprF (94) que parecen incrementar la actividad de esta enzima, contribuyendo al incremento de la carga positiva de la superficie celular (94-96). El operón dlt $A B C$, responsable de la adición de D-alanina a los ácidos teicoicos (lo que aumenta la carga positiva de la membrana), también se ha relacionado con la reducción de la sensibilidad a la daptomicina (97) y, por último, las mutaciones puntuales en los genes rpoB y rpoC (que codifican para las subunidades $B$ y $B^{\prime}$ de la ARN polimerasa, respectivamente), se han asociado, igualmente, con la aparición de la resistencia a la daptomicina en $S$. aureus $(92,98)$.

El segundo grupo corresponde a genes que codifican sistemas reguladores de dos componentes que permiten a las bacterias censar y responder a cambios en el ambiente, y que en su forma clásica están constituidos por una proteína cinasa (sensor) y un regulador de respuesta (regulador de transcripción) (99). El sistema regulador de dos componentes YycFG se ha relacionado con el desarrollo de la resistencia a la daptomicina en cepas clínicas y de laboratorio $(92,100)$. Otro sistema regulador de dos componentes relacionado con el desarrollo de la resistencia a la daptomicina es el vraSR (también relacionado con el desarrollo de $S$. aureus de sensibilidad intermedia a la vancomicina), el cual se ha encontrado sobreexpresado en cepas resistentes a la daptomicina. Aún más, la inactivación de estos genes en dichas cepas revierte la sensibilidad a este antibiótico (101). Por último, los 
genes vraF (proteína transportadora de tipo $A B C$ ) y vraG (proteína transportadora de tipo permeasa) también han sido asociados con el desarrollo de resistencia a la daptomicina en S. aureus (102).

El tercer grupo incluye genes que codifican enzimas implicadas en el metabolismo de los fosfolípidos. Los genes que más se han estudiado en este grupo son los responsables de la síntesis de la cardiolipina, un fosfolípido crítico para la membrana celular bacteriana (103). De hecho, $S$. aureus posee dos genes que codifican para la sintetasa de cardiolipina $(c / s)$ y es importante anotar que el cls2 es el que se ha relacionado con la resistencia a la daptomicina en $S$. aureus. La enzima Cls contiene dos dominios transmembrana y dos dominios putativos de la sintetasa de cardiolipina (104); los cambios aminoacídicos en estos dominios se han asociado con el desarrollo de la resistencia a la daptomicina; más aún, la presencia simultánea de sustituciones en Cls y MprF parece ser importante en el mecanismo de 'repulsión' de la superficie celular exhibido por la daptomicina, aunque también se ha postulado que puede contribuir a la alteración de la interacción del compuesto con los fosfolípidos de la membrana celular (105). Otro de los genes implicados en la resistencia a la daptomicina es el $p g s A$, el cual codifica para una CDP-diacilglicerolglicerol-3-fosfato-3-fosfatidiltransferasa, enzima involucrada en la síntesis de FG en la que Peleg, et al., identificaron una mutación puntual en pgsA que incrementó la CIM frente a la daptomicina en $S$. aureus (de $0,5 \mu \mathrm{g} / \mathrm{ml}$ a $2 \mu \mathrm{g} / \mathrm{ml}$ ) (105).

\section{Resistencia a la daptomicina en enterococos}

Aunque la sensibilidad a la daptomicina en enterococos aún es muy alta (>99\%), el uso de este antibiótico para tratar infecciones graves por enterococos resistentes a la vancomicina se ha incrementado sustancialmente debido a la falta de mejores opciones. Esto ha hecho que los reportes de resistencia y fracaso del tratamiento también se hayan incrementado en todo el mundo (106111) (Munita JM, Álvarez D, Bayer AS, Panesso $\mathrm{D}$, Tran TT, Reyes J, et al. Mutations in LiaSR in vancomycin-resistant $E$. faecium (VRE) predict clinical daptomycin treatment failure. Poster C1316. Interscience Conference on Antimicrobial Agents and Chemotherapy (ICAAC), Denver, September 10-13, 2013). De forma similar a lo que sucede en $S$. aureus, la resistencia a la daptomicina en enterococos se ha asociado fundamentalmente con los sistemas reguladores que orquestan la respuesta al estrés de la envoltura celular y con los genes que regulan el metabolismo de los fosfolípidos (figura 1B, cuadro 1). En esta sección discutimos, además, el papel de algunas proteínas que también se han asociado con el desarrollo de la resistencia a la daptomicina en enterococos.

El sistema liaFSR codifica un sistema regulador de tres componentes (homólogo del VraSR en S. aureus) formado por LiaS (histidina cinasa), LiaR (regulador de respuesta) y LiaF (proteína transmembrana que en $B$. subtilis es un regulador negativo de LiaS). Este sistema está involucrado en la respuesta a daños de la envoltura celular, incluidos los péptidos antimicrobianos y los antibióticos que actúan en la pared y membrana celular $(112,113)$. Con relación a la daptomicina, el liaFSR parece jugar un papel fundamental en el desarrollo de la resistencia y la tolerancia de los enterococos a este antibiótico. Así, la deleción de un solo aminoácido $(\Delta 177 \mathrm{lle})$ en la LiaF elevó la CIM de daptomicina en un aislamiento clínico de $E$. faecalis de 1 a $4 \mu \mathrm{g} / \mathrm{ml}$, situándola justo en el punto de corte establecido por el CLSI (110).

Por otra parte, un estudio que analizó cepas provenientes de muestras de bacteriemias causadas por $E$. faecium encontró que $75 \%$ de los aislamientos con CIM para daptomicina de entre 3 y $4 \mu \mathrm{g} / \mathrm{ml}$ (cercanas al punto de corte) ya presentaba cambios en el liaFSR, hallazgo que contrastó con el hecho de que ninguna de las cepas con $\mathrm{CIM} \leq 2$ $\mu \mathrm{g} / \mathrm{ml}$ presentó mutaciones en dicho sistema (114). Si bien no hay evidencia sólida que relacione la presencia de mutaciones en liaFSR con el fracaso terapéutico, algunos estudios in vitro demuestran que los cambios antes mencionados en LiaF ( $E$. faecalis) y en LiaSR ( $E$. faecium) fueron suficientes para abolir la actividad bactericida de la daptomicina contra estas cepas de enterococo $(114,115)$. Por el momento, la única información clínica disponible es la de un paciente con bacteriemia por $E$. faecium $(\mathrm{CIM}=3 \mu \mathrm{g} / \mathrm{ml})$, la cual persistió después del tratamiento con daptomicina (dosis de $8 \mathrm{mg} / \mathrm{kg}$ ). Los análisis moleculares de esta cepa mostraron la presencia de mutaciones en el liaFSR (115), las cuales se han identificado en otras cepas clínicas de E. faecium con CIM cercanas al punto de corte.

En relación con el mecanismo por el cual el liaFSR contribuye a la resistencia a la daptomicina en E. faecalis, una publicación reciente sugiere que los cambios en dicho sistema resultan en una redistribución de microdominios de cardiolipina en la membrana celular, los cuales se localizan en sitios distantes del septo celular (donde se realiza 
la división bacteriana). Se ha postulado que este cambio topológico está asociado a una movilidad de la daptomicina en sitios lejanos del septo celular con el fin de preservar esta estructura vital en el metabolismo bacteriano (116). Por último, en $E$. faecium se ha descrito otro sistema regulador de dos componentes que se denomina YycFG (con genes accesorios), que parece ser una vía alternativa para el desarrollo de la resistencia a la daptomicina en estos microorganismos (110).

Además, la comparación genómica de dos cepas isogénicas de $E$. faecalis (una sensible a la daptomicina, DAP-S, y su derivado resistente, DAP-R) indicó que, aparte del sistema liaFSR, la presencia de cambios en dos enzimas relacionadas con el metabolismo de fosfolípidos era un elemento importante en el mecanismo de resistencia a la daptomicina. El primer gen $(g d p D)$ codifica para una glicerol-fosfodiesterasa (GdpD) que participa en el metabolismo del glicerol a través de la hidrólisis de fosfodiésteres. Esta mutación no parece afectar la sensibilidad a la daptomicina por sí sola, sin embargo, completa el fenotipo de resistencia cuando se encuentra en presencia de cambios en la LiaF (110). El segundo gen corresponde al cls, el cual codifica para la sintetasa de cardiolipina $(\mathrm{Cls})$ y ha sido postulado, asimismo, como responsable de la aparición de resistencia a la daptomicina en $E$. faecium y en $S$. aureus (véase el acápite anterior). Algunos estudios recientes han señalado que las sustituciones observadas en esta enzima incrementan su actividad catalítica, lo que podría actuar directamente sobre el fosfatidilglicerol de la membrana celular (117). El papel de los cambios en la Cls no está del todo claro y hay información contradictoria en la literatura científica. Palmer, et al., demostraron que la sobreexpresión de una $\mathrm{Cls}$ mutada en una cepa de laboratorio de $E$. faecalis (OG1RF) aumentó la CIM de la daptomicina de $4 \mu \mathrm{g} / \mathrm{ml}$ a $64 \mu \mathrm{g} / \mathrm{ml}$ (118). Sin embargo, Tran, et al., no observaron cambios en la sensibilidad a la daptomicina al introducir la misma mutación a través de reemplazo alélico en una cepa de $E$. faecium (111). Otro gen identificado como posible responsable del desarrollo de la resistencia a la daptomicina es el cfa, que codifica para una sintetasa de ciclopropano involucrada en la síntesis de ácidos grasos (111).

En conjunto, estos hallazgos sugieren que una estrategia común para desarrollar resistencia a la daptomicina se basa en la modulación de los genes que controlan la respuesta en la superficie y en la membrana celular, involucrando sistemas de señalización celular como el liaFSR o el YycFG, los cuales juegan un papel fundamental para el desarrollo de la resistencia a la daptomicina.

\section{Resistencia a la tigeciclina}

Las glicilciclinas fueron desarrolladas con el fin de superar los mecanismos de resistencia a las tetraciclinas, los cuales están ampliamente distribuidos (119-121). La tigeciclina es el primer antibiótico de esta clase y se compone de una 9-t-butilglicilamida adjunta a la molécula de minociclina, lo que hace que pueda evadir la acción de las bombas de expulsión y no verse afectada por el mecanismo de 'protección ribosómica' que expresan algunas bacterias, el cual probablemente responde al impedimento estérico de la larga cadena en la posición 9 del anillo de la tetraciclina (121-123). Al igual que las tetraciclinas, la tigeciclina inhibe la síntesis de las proteínas mediante la inhibición de la unión alostérica del aminoacilARNt en el sitio aceptor (sitio A) de la subunidad ribosómica 30S (120); sin embargo, su afinidad por el sitio ribosómico es mayor que la del resto de las tetraciclinas (124).

La tigeciclina fue aprobada en el 2005 por la FDA para el tratamiento de infecciones de la piel y tejidos blandos e infecciones intraabdominales complicadas, y en el 2009 para el manejo de la neumonía bacteriana de origen comunitario (125). El medicamento presenta un amplio espectro de actividad contra los microorganismos Gram positivos, Gram negativos y anaerobios (123), especialmente contra SARM, S. epidermidis resistente a la meticilina y enterococos (incluidos los resistentes a la vancomicina) (125). Si bien es cierto que el CLSI no ha definido puntos de corte para la tigeciclina, provisionalmente se ha propuesto denominar como sensibles a aquellos aislamientos con CIM $<2 \mu \mathrm{g} / \mathrm{ml}$ y como resistentes a aquellos con $\mathrm{CIM}>8 \mu \mathrm{g} / \mathrm{ml}$ (126). La sensibilidad a la tigeciclina es muy alta, y la aparición de resistencia es un fenómeno poco frecuente. En este sentido puede mencionarse un informe de vigilancia realizada entre 2004 y 2011 en el que se estudiaron 9.422 cepas de Gram positivos en Estados Unidos, Europa y Latinoamérica y en el que se determinó que $S$. aureus, $S$. pneumoniae, E. faecalis y E. faecium presentaron $100 \%$ de sensibilidad a este antibiótico (127). Resultados similares se han hallado en reportes que incluían aislamientos de SARM y de enterococos resistentes a la vancomicina de distintos países del mundo, incluido Colombia $(125,128,129)$. 
Sin perjuicio de lo dicho, la resistencia a la tigeciclina en Gram positivos sí se ha descrito; en el 2008, por ejemplo, se reportó en Alemania el primer aislamiento de $E$. faecalis resistente a la tigeciclina, el cual fue aislado de la orina de un paciente que recibía tigeciclina como tratamiento contra una infección respiratoria ocasionada por Stenotrofomonas maltophilia (130). Posteriormente, en el 2011, se detectó un nuevo aislamiento de $E$. faecalis resistente a la tigeciclina, esta vez en el Reino Unido, a partir de hemocultivos de un paciente con sepsis intraabdominal complicada; en ninguno de estos casos se dilucidó el mecanismo de resistencia (131).

\section{Resistencia a cefalosporinas de última generación}

La ceftarolina es una oximino-cefalosporina derivada de la cefosopra (cefalosporina de cuarta generación) que tiene actividad bactericida y se administra de forma parenteral. La formulación disponible es el profármaco ceftarolina fosamil, el cual se convierte rápidamente en ceftarolina mediante la acción de fosfatasas plasmáticas (132). La ceftarolina pertenece a una nueva clase de cefalosporinas con actividad contra SARM que algunos denominan 'cefalosporinas de quinta generación' (132) y que fue aprobada por la FDA para el tratamiento de adultos con infecciones complicadas de piel y tejidos blandos adquiridas en la comunidad $(133,134)$. Su espectro de acción es muy amplio e incluye SARM, S. aureus de sensibilidad intermedia a la vancomicina, $S$. epidermidis resistente y sensible a la meticilina y $S$. pneumoniae con sensibilidad reducida a penicilina, eritromicina, amoxicicilina, fluoroquinolonas y cefotaxima (135).

En cuanto a los enterococos, la ceftarolina presenta actividad in vitro contra $E$. faecalis resistente y sensible a la vancomicina, pero no así contra $E$. faecium, $(133,135)$. Su mecanismo de acción es similar al de otros betalactámicos, pues interfiere en la síntesis de la pared celular mediante la unión a las proteínas de unión a penicilina (PBP) (132). Específicamente, la ceftarolina presenta buena afinidad por las cuatro PBP de $S$. aureus, así como una alta afinidad por la PBP2a, que es codificada por el gen $m e c A$ y es responsable de la resistencia a la meticilina en $S$. aureus. La ceftarolina también se une a las seis PBP que han sido identificadas en S. pneumoniae: PBP1a, 1b, 2x, 2a-b y 3 (133). A la fecha no se ha reportado resistencia a la ceftarolina en aislamientos clínicos, y distintas publicaciones han demostrado que la $\mathrm{CIM}_{50}$ y la $\mathrm{CIM}_{90}$ para
SARM es de 0,5 y $1 \mu \mathrm{g} / \mathrm{ml}$, respectivamente, valores que se repiten en $S$. pneumoniae sensible a la penicilina (136). Aunque sigue siendo activa, la ceftarolina en $E$. faecalis presenta CIM más altas, con una $\mathrm{CIM}_{50}$ de $2 \mu \mathrm{g} / \mathrm{ml}$ y una $\mathrm{CIM}_{90}$ de $4 \mu \mathrm{g} / \mathrm{ml}$ $(133,135)$. Algunos estudios in vitro de selección de cepas resistentes, incluidas cepas de SARM-AC, $S$. aureus con heterorresistencia a la vancomicina, $S$. aureus sensible a la meticilina y $S$. pneumoniae resistente a la penicilina, no detectaron altos niveles de resistencia, lo que sugiere que la probabilidad de la emergencia de resistencia in vivo frente a esta nueva cefalosporina es baja $(132,137,138)$.

Un medicamento relacionado con la cefatarolina es el ceftobiprol, el cual fue la primera cefalosporina desarrollada con actividad contra SARM (139). Es una pirrolidinona de administración intravenosa y actividad bactericida cuyo espectro de acción es amplio, pues abarca bacterias Gram positivas multirresistentes, como SARM, $S$. aureus de sensibilidad intermedia a la vancomicina, $S$. aureus resistente a la vancomicina, $E$. faecalis resistente a la vancomicina y $S$. pneumoniae resistente a la penicilina (140). Sin embargo, al igual que la ceftarolina, no presenta actividad contra $E$. faecium y, a diferencia de la ampicilina, mantiene su actividad en altos inóculos bacterianos (141), lo que sumado a su baja interacción con otros medicamentos y a su buen perfil de seguridad, la convierte en una alternativa terapéutica potencialmente atractiva. Sin embargo, el medicamento solo está disponible en Suiza y Canadá. Su utilidad clínica se ha evaluado en infecciones complicadas de piel y en neumonías adquiridas en la comunidad, pero su uso clínico aún no ha sido aprobado.

Los altos niveles de resistencia in vitro al ceftobiprol en aislamientos de SARM se han asociado en un estudio con mutaciones en el gen que codifica para la PBP2a $(m e c A)$. Las cepas resistentes se obtuvieron en cultivos sucesivos con concentraciones por debajo del umbral inhibitorio que fueron incrementados empleando altos inóculos bacterianos. Se postularon tres mecanismos involucrados en la resistencia in vitro: la inhibición de la unión al substrato, la interferencia de la interacción proteína-proteína y la inhibición de la acilación. También se detectó resistencia en cepas que no presentaban el gen $m e c A$ y que, por lo tanto, no expresaban la proteína, por lo que se postuló que otros genes cromosómicos tendrían efecto en la resistencia a ceftobiprol (142). 


\section{Conclusiones}

La resistencia a los antibióticos se considera uno de los problemas primordiales de salud pública en el mundo, ya que constituye un desafío tanto en el plano de la epidemiología como del tratamiento farmacológico de las enfermedades infecciosas.

Entre los patógenos emergentes, SARM y los enterococos resistentes a la vancomicina presentan frecuentemente resistencia múltiple y plantean importantes retos para la terapéutica médica.

Entre los nuevos fármacos disponibles se destaca la presencia de agentes con actividad contra bacterias Gram positivas multirresistentes, pero la alta capacidad de adaptación de las bacterias las lleva a desarrollar mecanismos de resistencia con una velocidad preocupante.

Ya se dispone de nuevas alternativas terapéuticas como la daptomicina, el linezolid, la tigeciclina y las cefalosporinas con actividad contra SARM para el manejo de estos microorganismos, y otras están en fases avanzadas de los estudios clínicos. Dichos compuestos han demostrado ser efectivos, pero su uso ha de ser racional.

El desarrollo de estrategias terapéuticas innovadoras parece ser fundamental para alcanzar el éxito clínico $(38,143)$ y, aunque la resistencia a estos nuevos agentes es poco común, la aparición de aislamientos resistentes revela la potencial amenaza de la emergencia de resistencia en el futuro.

La lucha contra los microorganismos resistentes es continua, pues la gran capacidad de adaptación de los Gram positivos de importancia clínica continuará planteando retos importantes para la medicina mundial a corto y largo plazo.

\section{Conflicto de intereses}

No hay conflicto de intereses que declarar.

\section{Financiación}

Cesar A. Arias es financiado por el National Institute of Allergy and Infectious Diseases (NIAID-NIH), R01 Al093749. La redacción del manuscrito se realizó durante el tiempo de contrato de los investigadores en la Universidad El Bosque y en la University of Texas Medical School at Houston.

\section{Referencias}

1. Woodfor N, Livermore DM. Infections caused by Grampositive bacteria: A review of the global challenge. J Infect. 2009;59(Supl.1):S4-S16. http://dx.doi.org/10.1016/S01634453(09)60003-7
2. Livermore DM. Has the era of untreatable infections arrived? J Antimicrob Chemother. 2009;64(Supl.1):i29-36. http://dx.doi. org/10.1093/jac/dkp255

3. Arias CA, Murray BE. Antibiotic-resistant bugs in the $21^{\text {st }}$ century: A clinical super-challenge. N Engl J Med. 2009; 360:439-43. http://dx.doi.org/10.1056/NEJMp0804651

4. Peterson LR. Bad bugs, no drugs: No ESCAPE revisited. Clin Infect Dis. 2009;49:992-3. http://dx.doi.org/10.1086/605539

5. Chambers HF, Deleo FR. Waves of resistance: Staphylococcus aureus in the antibiotic era. Nat Rev Microbiol. 2009;7:629-41. http://dx.doi.org/10.1038/nrmicro2200

6. Reyes J, Rincón S, Díaz L, Panesso D, Contreras GA, Zurita J, et al. Dissemination of methicillin-resistant Staphylococcus aureus USA300 sequence type 8 lineage in Latin America. Clin Infect Dis. 2009;49:1861-7. http://dx.doi. org/10.1086/648426

7. Arias CA, Rincón S, Chowdhury S, Martínez E, Coronell W, Reyes J, et al. MRSA USA300 clone and VREF: A U.S.Colombian connection? N Engl J Med. 2008;359:2177-9. http://dx.doi.org/10.1056/NEJMc0804021

8. van Hal SJ, Fowler VG Jr. Is it time to replace vancomycin in the treatment of methicillin-resistant Staphylococcus aureus infections? Clin Infect Dis. 2013;56:1779-88. http://dx. doi.org/10.1093/cid/cit178

9. Kollef MH. Limitations of vancomycin in the management of resistant staphylococcal infections. Clin Infect Dis. 2007; 45:S191-5. http://dx.doi.org/10.1086/519470

10. Micek ST. Alternatives to vancomycin for the treatment of methicillin-resistant Staphylococcus aureus infections. Clin Infect Dis. 2007;45:S184-90. http://dx.doi.org/10.1086/ 519471

11. Deresinski S. Counterpoint: Vancomycin and Staphylococcus aureus- an antibiotic enters obsolescence. Clin Infect Dis. 2007;44:1543-8. http://dx.doi.org/10.1086/518452

12. van Hal SJ, Lodise TP, Paterson DL. The clinical significance of vancomycin minimum inhibitory concentration in Staphylococcus aureus infections: A systematic review and meta-analysis. Clin Infect Dis. 2012;54:755-71. http://dx. doi. org/10.1093/cid/cir935

13. Clinical and Laboratory Standards Institute. Performance standards for antimicrobial susceptibility testing twenty-first informational supplement M100-S21. Wayne, PA: CLSI; 2012.

14. Hiramatsu K, Aritaka N Hanaki H, Kawasaki S, Hosoda Y, Hori S, et al. Dissemination in Japanese hospitals of strains of Staphylococcus aureus heterogeneously resistant to vancomycin. Lancet. 1997;350:1670-3. http://dx.doi.org/10. 1016/S0140-6736(97)07324-8

15. Howden BP, Davies JK, Johnson PD, Stinear TP, Grayson ML. Reduced vancomycin susceptibility in Staphylococcus aureus, including vancomycin-intermediate and heterogeneous vancomycin-intermediate strains: Resistance mechanisms, laboratory detection, and clinical implications. Clin Microbiol Rev. 2010;23:99-139. http://dx.doi.org/10.1128/ CMR.00042-09

16. Hiramatsu K, Hanaki H, Ino T, Yabuta K, Oguri T, Tenover FC. Methicillin-resistant Staphylococcus aureus clinical strain with reduced vancomycin susceptibility. J Antimicrob Chemother. 1997;40:135-6. http://dx.doi.org/10. 1093/jac/40.1.135 
17. Fridkin S, Hageman KJ, McDougal LK, Mohammed J, Jarvis WR, Perl TM, et al. Epidemiological and microbiological characterization of infections caused by Staphylococcus aureus with reduced susceptibility to vancomycin, United States, 1997-2001. Clin Infect Dis. 2003;36:429-39. http://dx.doi.org/10.1086/346207

18. Howden BP, Ward PB, Charles PG, Korman TM, Fuller A, duCros $\mathbf{P}$, et al. Treatment outcomes for serious infections caused by methicillin-resistant Staphylococcus aureus with reduced vancomycin susceptibility. Clin Infect Dis. 2004;38:521-8. http://dx.doi.org/10.1086/381202

19. Charles PG, Ward PB, Johnson PD, Howden PB, Grayson ML. Clinical features associated with bacteremia due to heterogeneous vancomycin-intermediate Staphylococcus aureus. Clin Infect Dis. 2004;38:448-51. http://dx.doi.org/10. $1086 / 381093$

20. Hafer C, Lin Y, Kornblum J, Lowy FD, Uhlemann AC. Contribution of selected gene mutations to resistance in clinical isolates of vancomycin-intermediate Staphylococcus aureus. Antimicrob Agents Chemother. 2012;56:5845-51. http://dx.doi.org/10.1128/AAC.01139-12

21. Hanaki H, Kuwahara-Arai K, Boyle-Vavra S, Daum RS, Labischinski H, Hiramatsu K. Activated cell-wall synthesis is associated with vancomycin resistance in methicillinresistant Staphylococcus aureus clinical strains Mu3 and Mu50. J Antimicrob Chemother 1998;42:199-209. http://dx. doi.org/10.1093/jac/42.2.199

22. Cui L, Ma X, Sato K, Okuma K, Tenover FC, Mamizuka EM, et al. Cell wall thickening is a common feature of vancomycin resistance in Staphylococcus aureus. J Clin Microbiol. 2003;41:5-14. http://dx.doi.org/10.1128/JCM.41.1. 5-14.2003

23. Centers for Disease Control and Prevention. Staphylococcus aureus resistant to vancomycin-United States, 2002. MMWR Morb Mortal Wkly Rep. 2002;51:565-7.

24. Chang S, Sievert DM, Hageman JC, Boulton ML, Tenover FC, Downes FP, et al. Infection with vancomycin-resistant Staphylococcus aureus containing the vanA resistance gene. N Engl J Med. 2003;348:1342-7. http://dx.doi.org/10. 1056/NEJMoa025025

25. Sievert DM, Rudrik JT, Patel JB, McDonald LC, Wilkins MJ, Hageman JCN. Vancomycin-resistant Staphylococcus aureus in the United States, 2002-2006. Clin Infect Dis. 2008;46:668-74. http://dx.doi.org/10.1086/527392

26. Aligholi M, Emaneini M, Jabalameli F, Shahsavan S, Dabiri H, Sedaght H. Emergence of high-level vancomycinresistant Staphylococcus aureus in the Imam Khomein Hospital in Tehran. Med Princ Pract. 2008;17:432-4. http://dx. doi.org/10.1159/000141513

27. Tiwari HK, Sen MR. Emergence of vancomycin resistant Staphylococcus aureus (VRSA) from a tertiary care hospital from northern part of India. BMC Infect Dis. 2006;6:156. http://dx.doi.org/10.1186/1471-2334-6-156

28. Saha B, Singh AK, Ghosh A, Bal M. Identification and characterization of a vancomycin-resistant Staphylococcus aureus isolated from Kolkata (South Asia). J Med Microbiol. 2008;57:72-9. http://dx.doi.org/10.1099/jmm.0.47144-0

29. Weigel LM, Clewell DB, Gill SR, Clark NC, McDougal LK, Flannagan SE. Genetic analysis of a high-leve vancomycin-resistant isolate of Staphylococcus aureus.
Science. 2003:28;302:1569-71. http://dx.doi.org/10.1126/ science. 1090956

30. Kos VN, Desjardins CA, Griggs A, Cerqueira G, Van Tonder A, Holden MT, et al. Comparative genomics of vancomycin-resistant Staphylococcus aureus strains and their positions within the clade most commonly associated with methicillin-resistant $S$. aureus hospital-acquired infection in the United States. MBio. 2012;3. http://dx.doi.org/10.1128/ mBio.00112-12

31. Tenover FC, Goering RV. Methicillin-resistant Staphylococcus aureus strain USA300: Origin and epidemiology. J Antimicrob Chemother. 2009;64:441-6. http://dx.doi.org/10. 1093/jac/dkp241

32. Arias CA, Murray BE. The rise of the Enterococcus: Beyond vancomycin resistance. Nat Rev Microbiol. 2012;10:266-78. http://dx.doi.org/10.1038/nrmicro2761

33. Arias CA, Murray BE. Emergence and management of drugresistant enterococcal infections. Expert Rev Anti Infect Ther. 2008;6:637-55. http://dx.doi.org/ 0.1586/14787210.6.5.637

34. Galloway-Peña JR, Nallapareddy SR, Arias CA, Eliopoulos GM, Murray BE. Analysis of clonality and antibiotic resistance among early clinical isolates of Enterococcus faecium in the United States. J Infect Dis. 2009;200:1566-73. http://dx.doi.org/10.1086/644790.

35. de Been M, van Schaik W, Cheng L, Corander J, Willems R. Recent recombination events in the core genome are associated with adaptive evolution in Enterococcus faecium. Genome Biol Evol. 2013;5:1524-35. http://dx.doi. org/10.1093/gbe/evt111

36. Lebreton F, van Schaik W, McGuire AM, Godfrey P, Griggs A, Mazumdar V, et al. Emergence of epidemic multidrug-resistant Enterococcus faecium from animal and commensal strains. MBio. 2013;4. http://dx.doi.org/10.1128/ mBio.00534-13

37. Freire-Moran L, Aronsson B, Manz C, Gyssens IC, So AD, ECDC-EMA Working Group, et al. Critical shortage of new antibiotics in development against multidrug-resistant bacteria - Time to react is now. Drug Resist Updat. 2011;14:118-24. http://dx.doi.org/10.1016/j. drup.2011.02.003

38. Eliopoulos GM. Microbiology of drugs for treating multiple drug-resistant Gram-positive bacteria. J Infect. 2009;59:S1724. http://dx.doi.org/10.1016/S0163-4453(09)60004-9

39. Pérez F, Salata RA, Bonomo RA. Current and novel antibiotics against resistant Gram-positive bacteria. Infect Drug Resist. 2008;1:27-44.

40. Senior K. FDA approves first drug in new class of antibiotics. Lancet. 2000;355:1523. http://dx.doi.org/10.1016/S0140-6736 (00)02173-5

41. Brickner SJ, Barbachyn MR, Hutchinson DK, Manninen PR. Linezolid (ZYVOX), the first member of a completely new class of antibacterial agents for treatment of serious Gram-positive infections. J Med Chem. 2008;51:1981-90. http://dx.doi.org/10.1021/jm800038g

42. Wilson DN, Schluenzen F, Harms JM, Starosta AL, Connell SR, Fucini P. The oxazolidinone antibiotics perturb the ribosomal peptidyl-transferase center and effect tRNA positioning. Proc Natl Acad Sci USA. 2008;105:13339-44. http://dx.doi.org/10.1073/pnas.0804276105 
43. Tsiodras S, Gold HS, Sakoulas G, Eliopoulos GM, Wennersten C, Venkataraman L, et al. Linezolid resistance in a clinical isolate of Staphylococcus aureus. Lancet. 2001;358:207-8. http://dx.doi.org/10.1016/S01406736(01)05410-1

44. Balode A, Punda-Polić V, Dowzicky MJ. Antimicrobial susceptibility of Gram-negative and Gram-positive bacteria collected from countries in Eastern Europe: Results from the Tigecycline Evaluation and Surveillance Trial (T.E.S.T.) 2004-2010. Int J Antimicrob Agents. 2013;41:527-35. http:// dx.doi.org/10.1016/j.ijantimicag.2013.02.022

45. Flamm RK, Farrell DJ, Mendes RE, Ross JE, Sader HS, Jones RN. LEADER Surveillance program results for 2010: An activity and spectrum analysis of linezolid using 6801 clinical isolates from the United States (61 medical centers). Diagn Microbiol Infect Dis. 2012;74:54-61. http://dx.doi. org/10.1016/j.diagmicrobio.2012.05.012

46. Flamm RK, Mendes RE, Ross JE, Sader HS, Jones RN. An international activity and spectrum analysis of linezolid: ZAAPS Program results for 2011. Diagn Microbiol Infect Dis. 2013;76:206-13. http://dx.doi.org/10.1016/j. diagmicrobio.2013.01.025

47. Sader HS, Flamm RK, Jones RN. Antimicrobial activity of daptomycin tested against Gram-positive pathogens collected in Europe, Latin America, and selected countries in the Asia-Pacific Region (2011). Diagn Microbiol Infect Dis. 2013;75;417-22. http://dx.doi.org/10.1016/j.diagmicrobio. 2013.01.001

48. Zhanel GG, Adam HJ, Baxter MR, Fuller J, Nichol KA, Denisuik AJ, et al. Anti-microbial susceptibility of 22746 pathogens from Canadian hospitals: Results of the CANWARD 2007-11 study. J Antimicrob Chemother. 2013;68:i7-23. http://dx.doi.org/10.1093/jac/dkt022

49. Locke JB, Hilgers M, Shaw KJ. Mutations in ribosomal protein L3 are associated with oxazolidinone resistance in staphylococci of clinical origin. Antimicrob Agents Chemother. 2009;53:5275-8 http://dx.doi.org/10.1128/AAC. 01032-09

50. Mendes RE, Deshpande LM, Farrell DJ, Spanu T, Fadda G, Jones RN. Assessment of linezolid resistance mechanisms among Staphylococcus epidermidis causing bacteraemia in Rome, Italy. J Antimicrob Chemother. 2010;65:2329-35. http://dx.doi.org/10.1093/jac/dkq331

51. Toh SM, Xiong L, Arias CA, Villegas MV, Lolans K, Quinn $\mathrm{J}$, et al. Acquisition of a natural resistance gene renders a clinical strain of methicillin-resistant Staphylococcus aureus resistant to the synthetic antibiotic linezolid. Mol Microbiol. 2007;64:1506-14.http://dx.doi.org/10.1111/j.1365-2958.2007. 05744.x

52. Long KS, Vester B. Resistance to linezolid caused by modifications at its binding site on the ribosome. Antimicrob Agents Chemother. 2012;56:603-12. http://dx.doi.org/10. 1128/AAC.05702-11

53. Besier S, Ludwig A, Zande, J, Brade V, Wichelhaus TA. Linezolid resistance in Staphylococcus aureus: Gene dosage effect, stability, fitness costs, and cross-resistances. Antimicrob Agents Chemother. 2008;52:1570-2. http://dx. doi.org/10.1128/AAC.01098-07

54. Burleson BS, Ritchie DJ, Micek ST, Dunne WM. Enterococcus faecalis resistant to linezolid: Case series and review of the literature. Pharmacotherapy. 2004;24:1225-31. http://dx.doi.org/10.1592/phco.24.13.1225.38086

55. Hill RL, Kearns AM, Nash J, North SE, Pike R, Newson $\mathrm{T}$, et al. Linezolid-resistant ST36 methicillin-resistant Staphylococcus aureus associated with prolonged linezolid treatment in two pediatric cystic fibrosis patients. J Antimicrob Chemother. 2010;65:442-5. http://dx.doi.org/10.1093/jac/ dkp494

56. Schwarz S, Werckenthin C, Kehrenberg C. Identification of a plasmid-borne chloramphenicol-florfenicol resistance gene in Staphylococcus sciuri. Antimicrob Agents Chemother. 2000;44:2530-3. http://dx.doi.org/10.1128/AAC.44.9.25302533.2000

57. Kehrenberg C, Ojo KK, Schwarz S. Nucleotide sequence and organization of the multiresistance plasmid pSCFS1 from Staphylococcus sciuri. J Antimicrob Chemother 2004; 54:936-9. http://dx.doi.org/10.1093/jac/dkh457

58. Kehrenberg C, Schwarz S. Distribution of florfenicol resistance genes fexA and cfr among chloramphenicolresistant Staphylococcus isolates. Antimicrob Agents Chemother. 2006;50:1156-63. http://dx.doi.org/10.1128/AAC. 50.4.1156-1163.2006

59. Kehrenberg C, Schwarz S. fexA, a novel Staphylococcus lentus gene encoding resistance to florfenicol and chloramphenicol. Antimicrob Agents Chemother. 2004;48: 615-8. http://dx.doi.org/10.1128/AAC.48.2.615-618.2004

60. Arias CA, Vallejo M, Reyes J, Panesso D, Moreno J, Castañeda $\mathrm{E}$, et al. Clinical and microbiological aspects of linezolid resistance mediated by the cfr gene encoding a 23S rRNA methyltransferase. J Clin Microbiol. 2008;46:892-6. http://dx.doi.org/10.1128/JCM.01886-07

61. Smith LK, Mankin AS. Transcriptional and translational control of the mlr operon, which confers resistance to seven classes of protein synthesis inhibitors. Antimicrob Agents Chemother. 2008;5:1703-812. http://dx.doi.org/10.1128/AAC. 01583-07

62. Mendes RE, Deshpande LM, Castanheira M, DiPersio J, Saubolle MA, Jones RN. First report of cfr-mediated resistance to linezolid in human staphylococcal clinical isolates recovered in the United States. Antimicrob Agents Chemother. 2008;52:2244-6. http://dx.doi.org/10.1128/AAC. 00231-08

63. Morales G, Picazo JJ, Baos E, Candel FJ, Arribi A, Peláez B, et al. Resistance to linezolid is mediated by the cfr gene in the first report of an outbreak of linezolid-resistant Staphylococcus aureus. Clin Infec. Dis. 2010;50:821-5. http://dx.doi.org/10.1086/650574

64. Locke JB, Morales G, Hilgers M, GC K, Rahawi S, José Picazo J, Shaw K, et al. Elevated linezolid resistance in clinical cfr-Positive Staphylococcus aureus isolates is associated with co-occurring mutations in ribosomal protein L3. Antimicrob Agents Chemother 2010;5:5352-5. http://dx. doi.org/10.1128/AAC.00714-10

65. Mendes RE, Deshpande L, Rodríguez-Noriega E, Ross JE, Jones RN, Morfín-Otero R. First report of Staphylococcal clinical isolates in Mexico with linezolid resistance caused by cfr. evidence of in vivo cfr mobilization. J Clin Microbiol. 2010;48:3041-3. http://dx.doi.org/10.1128/JCM.00880-10

66. Shore AC, Brennan OM, Ehricht R, Monecke S, Schwarz $\mathrm{S}$, Slickers $\mathbf{P}$, et al. Identification and characterization of 
the multidrug resistance gene cfr in a Panton-Valentine leukocidin-positive sequence type 8 methicillin-resistant Staphylococcus aureus IVa (USA300) isolate. Antimicrob Agents Chemother. 2010;54:4978-84. http://dx.doi.org/10. 1128/AAC.01113-10

67. Liu Y, Wang Y, Wu C, Shen Z, Schwarz S, Du XD, et al. First report of the multidrug resistance gene cfr in Enterococcus faecalis of animal origin. Antimicrob Agents Chemother. 2012;56:1650-4. http://dx.doi.org/10.1128/AAC.06091-11

68. Dai L, Wu CM, Wang MG, Wang Y, Wang Y, Huang SY, et al. First report of the multidrug resistance gene cfr and the phenicol resistance gene fexA in a Bacillus strain from swine feces. Antimicrob Agents Chemother. 2010;54:3953-5. http://dx.doi.org/10.1128/AAC.00169-10

69. Zhang WJ, Wu CM, Wang Y, Shen ZQ, Dai L, Han J, et al. The new genetic environment of $c f r$ on plasmid pBS-02 in a Bacillus strain. J Antimicrob Chemother. 2011;66:1174-5. http://dx.doi.org/10.1093/jac/dkr037

70. Díaz L, Kiratisin P, Mendes RE, Panesso D, Singh KV, Arias CA. Transferable plasmid-mediated resistance to linezolid due to cfr in a human clinical isolate of Enterococcus faecalis. Antimicrob Agents Chemother. 2012;56:3917-22. http://dx.doi.org/10.1128/AAC.00419-12

71. Patel SN, Memari N, Shahinas D, Toye B, Jamieson FB, Farrell DJ. Linezolid resistance in Enterococcus faecium isolated in Ontario, Canada. Diagn Microbiol Infect Dis. 2013;77:350-3. http://dx.doi.org/10.1016/j.diagmicrobio. 2013.08.012

72. LaMarre JM, Locke JB, Shaw KJ, Mankin AS. Low fitness cost of the multidrug resistance gene cfr. Antimicrob Agents Chemother. 2011;55:3714-9. http://dx.doi.org/10.1128/AAC. 00153-11

73. Díaz L, Kontoyiannis DP, Panesso D, Albert ND, Singh $\mathrm{KV}$, Tran TT, et al. Dissecting the mechanisms of linezolid resistance in a Drosophila melanogaster infection model of Staphylococcus aureus. J Infect Dis. 2013;208:83-91. http:// dx.doi.org/10.1093/infdis/jit138

74. Locke JB, Hilgers M, Shaw KJ. Novel ribosomal mutations in Staphylococcus aureus strains identified through selection with the oxazolidinones linezolid and torezolid (TR-700). Antimicrob Agents Chemother. 2009;53:5265-74. http://dx. doi.org/10.1128/AAC.00871-09

75. Robbel L, Marahiel MA. Daptomycin, a bacterial lipopeptide synthesized by a nonribosomal machinery. J Biol Chem 2010;36:27501-8. http://dx.doi.org/10.1074/jbc.R110.128181

76. Debono M, Abbott BJ, Molloy RM, Fukuda DS, Hunt AH, Daupert VM, et al. Enzymatic and chemical modifications of lipopeptide antibiotic A21978C: The synthesis and evaluation of daptomycin (LY146032). J Antibiot (Tokyo). 1988;8:1093105. http://dx.doi.org/10.7164/antibiotics.41.1093

77. González-Ruiz A, Beiras-Fernández A, Lehmkuhl H, Seaton RA, Loeffler J, Chaves RL. Clinical experience with daptomycin in Europe: The first 2.5 years. J Antimicrob Chemother. 2011;4:912-9. http://dx.doi.org/10.1093/jac/dkq528

78. Ernst CM, Staubitz P, Mishra NN, Yang SJ, Hornig $\mathbf{G}$, Kalbacher $\mathbf{H}$, et al. The bacterial defensin resistance protein MprF consists of separable domains for lipid lysinylation and antimicrobial peptide repulsion. PLoS Pathog. 2009;11:e1000660. http://dx.doi.org/10.1371/journal. ppat. 1000660
79. Straus SK, Hancock RE. Mode of action of the new antibiotic for Gram-positive pathogens daptomycin: Comparison with cationic antimicrobial peptides and lipopeptides. Biochim Biophys Acta. 2006;9:1215-23. http://dx.doi.org/10.1016/j. bbamem.2006.02.009

80. Jung D, Rozek A, Okon M, Hancock RE. Structural transitions as determinants of the action of the calciumdependent antibiotic daptomycin. Chem Biol. 2004;7:94957. http://dx.doi.org/10.1016/j.chembiol.2004.04.020

81. Eliopoulos GM, Thauvin C, Gerson B, Moellering RC Jr. In vitro activity and mechanism of action of A21978C1, a novel cyclic lipopeptide antibiotic. Antimicrob Agents Chemother. 1985;3:357-62. http://dx.doi.org/10.1128/AAC. 27.3.357

82. Muraih JK, Pearson A, Silverman J, Palmer M. Oligomerization of daptomycin on membranes. Biochim Biophys Acta. 2011;1808:1154-60. http://dx.doi.org/10.1016/ jbbamem.2011.01.001

83. Pogliano J, Pogliano N, Silverman JA. Daptomycinmediated reorganization of membrane architecture causes mislocalization of essential cell division proteins. J Bacteriol. 2012;17:4494-504. http://dx.doi.org/10.1128/JB.00011-12

84. Mariani PG, Sader HS, Jones RN. Development of decreased susceptibility to daptomycin and vancomycin in a Staphylococcus aureus strain during prolonged therapy. J Antimicrob Chemother. 2006;2:481-3. http://dx.doi.org/10. 1093/jac/dkl256

85. Sharma M, Riederer K, Chase P, Khatib R. High rate of decreasing daptomycin susceptibility during the treatment of persistent Staphylococcus aureus bacteremia. Eur J Clin Microbiol Infect Dis. 2008 6:433-7. http://dx.doi.org/10.1007/ s10096-007-0455-5

86. Hayden MK, Rezai K, Hayes RA, Lolans K, Quinn JP, Weinstein RA. Development of daptomycin resistance in vivo in methicillin-resistant Staphylococcus aureus. J Clin Microbiol. 2005;10:5285-7. http://dx.doi.org/10.1128/JCM. 43.10.5285-5287.2005

87. Skiest DJ. Treatment failure resulting from resistance of Staphylococcus aureus to daptomycin. J Clin Microbiol. 2006;2:655-6. http://dx.doi.org/10.1128/JCM.44.2.655-656. 2006

88. Sader HS, Jones RN. The activity of daptomycin against wild-type Staphylococcus aureus and strains with reduced susceptibility to vancomycin. Clin Infect Dis. 2006;43:798-9. http://dx.doi.org/10.1086/507109

89. Sader HS, Flamm RK, Jones RN. Antimicrobial activity of daptomycin tested against Gram-positive pathogens collected in Europe, Latin America, and selected countries in the Asia-Pacific Region (2011). Diagn Microbiol Infect Dis. 2013;75:417-22. http://dx.doi.org/10.1016/j.diagmicrobio. 2013.01.001

90. Jones T, Yeaman MR, Sakoulas G, Yang SJ, Proctor RA, Sahl HG, et al. Failures in clinical treatment of Staphylococcus aureus Infection with daptomycin are associated with alterations in surface charge, membrane phospholipid asymmetry, and drug binding. Antimicrob Agents Chemother. 2008;52:269-78. http://dx.doi.org/10. 1128/AAC.00719-07

91. Boyle-Vavra S, Jones M, Gourley BL, Holmes M, Ruf R, Balsam AR, et al. Comparative genome sequencing 
of an isogenic pair of USA800 clinical methicillin-resistant Staphylococcus aureus isolates obtained before and after daptomycin treatment failure. Antimicrob Agents Chemother. 2011;5:2018-25. http://dx.doi.org/10.1128/AAC.01593-10

92. Friedman L, Alder JD, Silverman JA. Genetic changes that correlate with reduced susceptibility to daptomycin in Staphylococcus aureus. Antimicrob Agents Chemother. 2006;6:2137-45. http://dx.doi.org/10.1128/AAC.00039-06

93. Mishra NN, Yang SJ, Sawa A, Rubio A, Nast CC, Yeaman MR, et al. Analysis of cell membrane characteristics of in vitro-selected daptomycin-resistant strains of methicillinresistant Staphylococcus aureus. Antimicrob Agents Chemother. 2009;6:2312-8. http://dx.doi.org/10.1128/AAC. 01682-08.

94. Jones T, Yeaman MR, Sakoulas G, Yang SJ, Proctor RA, Sahl HG, et al. Failures in clinical treatment of Staphylococcus aureus infection with daptomycin are associated with alterations in surface charge, membrane phospholipid asymmetry, and drug binding. Antimicrob Agents Chemother. 2008;52:269-78. http://dx.doi.org/10. 1128/AAC.00719-07

95. Ernst CM, Peschel A. Broad-spectrum antimicrobial peptide resistance by MprF-mediated aminoacylation and flipping of phospholipids. Mol Microbiol. 2011;80:290-9. http://dx.doi. org/10.1111/j.1365-2958.2011.07576.x

96. Mishra NN, Yang SJ, Chen L, Muller C, Saleh-Mghir A, Kuhn $\mathrm{S}$, et al. Emergence of daptomycin resistance in daptomycin-naïve rabbits with methicillin-resistant Staphylococcus aureus prosthetic joint infection is associated with resistance to host defense cationic peptides and $m p r F$ polymorphisms. PLoS One. 2013;8:e71151. http://dx.doi. org/10.1371/journal.pone.0071151

97. Yang SJ, Kreiswirth BN, Sakoulas G, Yeaman MR, Xiong YQ, Sawa A, et al. Enhanced expression of dltABCD is associated with the development of daptomycin nonsusceptibility in a clinical endocarditis isolate of Staphylococcus aureus. J Infect Dis. 2009;12:1916-20. http://dx.doi. org/10.1086/648473

98. Cui L, Isii T, Fukuda M, Ochiai T, Neoh HM, Camargo IL, et al. An RpoB mutation confers dual heteroresistance to daptomycin and vancomycin in Staphylococcus aureus. Antimicrob Agents Chemother. 2010;54:5222-33. http://dx. doi.org/10.1128/AAC.00437-10

99. Mascher T, Helmann JD, Unden G. Stimulus perception in bacterial signal-transducing histidine kinases. Microbiol Mol Biol Rev. 2006;70:910-38. http://dx.doi.org/10.1128/ MMBR.00020-06

100.Peleg AY, Miyakis S, Ward DV, Earl AM, Rubio A, Cameron DR, et al. Whole genome characterization of the mechanisms of daptomycin resistance in clinical and laboratory derived isolates of Staphylococcus aureus. PLoS One. 2012;7:e28316. http://dx.doi.org/10.1371/journal.pone. 0028316

101.Mehta S, Cuirolo AX, Plata KB, Riosa S, Silverman JA, Rubio A, et al. VraSR two-component regulatory system contributes to mprF-mediated decreased susceptibility to daptomycin in vivo-selected clinical strains of methicillinresistant Staphylococcus aureus. Antimicrob Agents Chemother. 2012;56:92-102. http://dx.doi.org/10.1128/AAC. 00432-10
102. Camargo IL, Neoh HM, Cui L, Hiramatsu K. Serial daptomycin selection generates daptomycin-nonsusceptible Staphylococcus aureus strains with a heterogeneous vancomycin-intermediate phenotype. Antimicrob Agents Chemother. 2008;52:4289-99. http://dx.doi.org/10.1128/ AAC.00417-08

103. Koprivnjak T, Zhang D, Ernst CM, Peschel A, Nauseef WM, Weiss JP. Characterization of Staphylococcus aureus cardiolipin synthases 1 and 2 and their contribution to accumulation of cardiolipin in stationary phase and within phagocytes. J Bacteriol. 2011;193:4134-42. http://dx. doi.org/10.1128/JB.00288-11.

104. Short SA, White DC. Biosynthesis of cardiolipin from phosphatidylglycerol in Staphylococcus aureus. J Bacteriol. 1972;109:820-6.

105. Peleg AY, Miyakis S, Ward DV, Earl AM, Rubio A, Cameron DR, et al. Whole genome characterization of the mechanisms of daptomycin resistance in clinical and laboratory derived isolates of Staphylococcus aureus. PLoS One. 2012;1:e28316. http://dx.doi.org/10.1371/journal. pone.0028316

106. Lewis JS 2nd, Owens A, Cadena J, Sabol K, Patterson JE, Jorgensen JH. Emergence of daptomycin resistance in Enterococcus faecium during daptomycin therapy. Antimicrob Agents Chemother. 2005;49:1664-5. http://dx. doi.org/10.1128/AAC.49.4.1664-1665.2005

107. Humphries RM, Kelesidis T, Tewhey R, Rose WE, Schork N, Nizet V, et al. Genotypic and phenotypic evaluation of the evolution of high-level daptomycin nonsusceptibility in vancomycin-resistant Enterococcus faecium. Antimicrob Agents Chemother. 2012;56:6051-3. http://dx.doi.org/10.1128/AAC.01318-12

108. Kelesidis T, Tewhey R, Humphries RM. Evolution of highlevel daptomycin resistance in Enterococcus faecium during daptomycin therapy is associated with limited mutations in the bacterial genome. J Antimicrob Chemother. 2013. 68:1926-8. http://dx.doi.org/10.1093/jac/dkt117

109. Muñoz-Price LS, Lolans K, Quinn JP. Emergence of resistance to daptomycin during treatment of vancomycinresistant Enterococcus faecalis infection. Clin Infect Dis. 2005;41:565-6. http://dx.doi.org/10.1086/432121

110. Arias CA, Panesso D, McGrath DM, Qin X, Mojica MF, Miller C, et al. Genetic basis for in vivo daptomycin resistance in enterococci. N Engl J Med. 2011;10:892-900. http://dx.doi.org/10.1056/NEJMoa1011138.

111. Tran TT, Panesso D, Gao H, Roh JH, Munita JM, Reyes $\mathrm{J}$, et al. Whole-genome analysis of a daptomycinsusceptible Enterococcus faecium strain and its daptomycinresistant variant arising during therapy. Antimicrob Agents Chemother. 2013;57:261-8. http://dx.doi.org/10.1128/AAC. 01454-12.

112. Suntharalingam $P$, Senadheera MD, Mair RW, Lévesque CM, Cvitkovitch DG. The LiaFSR system regulates the cell envelope stress response in Streptococcus mutans. J Bacteriol. 2009;9:2973-84. http://dx.doi.org/10.1128/JB. 01563-08

113. Jordan S, Hutchings MI, Mascher T. Cell envelope stress response in Gram-positive bacteria. FEMS Microbiol Rev. 2008;32:107-46. http://dx.doi.org/10.1111/j.1574-6976.2007. 00091.x 
114. Munita JM, Panesso D, Díaz L, Tran TT, Reyes J, Wanger $\mathbf{A}$, et al. Correlation between mutations in liaFSR of Enterococcus faecium and MIC of daptomycin: Revisiting daptomycin breakpoints. Antimicrob Agents Chemother. 2012:8:4354-9. http://dx.doi.org/10.1128/AAC. 00509-12

115. Munita JM, Tran TT, Díaz L, Panesso D, Reyes $\mathrm{J}$, Murray BE, et al. A liaF codon deletion abolishes daptomycin bactericidal activity against vancomycinresistant Enterococcus faecalis. Antimicrob Agents Chemother. 2013;6:2831-3. http://dx.doi.org/10.1128/AAC. 00021-13

116. Tran TT, Panesso D, Mishra NN, Mileykovskaya E, Guan Z, Munita JM, et al. Daptomycin-resistant Enterococcus faecalis diverts the antibiotic molecule from the division septum and remodels cell membrane phospholipids. MBio. 2013;4. http://dx.doi.org/10.1128/mBio. 00281-13

117. Davlieva M, Zhang W, Arias CA, Shamoo Y. Biochemical characterization of cardiolipin synthase mutations associated with daptomycin resistance in enterococci. Antimicrob Agents Chemother. 2013;1:289-96. http://dx.doi.org/10. 1128/AAC.01743-12

118. Palmer KL, Daniel A, Hardy C, Silverman J, Gilmore MS. Genetic basis for daptomycin resistance in enterococci. Antimicrob Agents Chemother. 2011;7:3345-56. http:// dx.doi.org/10.1128/AAC.00207-11

119. Chopra I, Roberts M. Tetracycline antibiotics: Mode of action, cations, molecular biology, and epidemiology of bacterial resistance. Microbiol Mol Biol Rev. 2001.65:232 60. http://dx.doi.org/10.1128/MMBR.65.2.232-260.2001

120. Griffin MO, Ceballos G, Villarreal FJ. Tetracycline compounds with non-antimicrobial organ protective properties: Possible mechanisms of action. Pharmacol Res. 2011;63:102-107. http://dx.doi.org/10.1016/j.phrs.2010.10.004

121. Ross JI, Eady E, Cove J, Cunliffe W. 16S-rRNA mutation associated with tetracycline resistance in a gram-positive bacterium. Antimicrob Agents Chemother. 1998;42:1702-5.

122. Doan TL, Fung HB, Mehta D, Riska PF. Tigecycline: A glycylcycline. Clin Ther. 2006;28:1079-106. http://dx.doi. org/10.1016/j.clinthera.2006.08.011

123. Pérez F. Current and novel antibiotics against resistant Gram-positive bacteria. Infect Drug Resist. 2008;1:27-44.

124. Karageorgopoulos DE, Kelesidis T, Kelesidis I, Falagas ME. Tigecycline for the treatment of multidrugresistant including carbapenem-resistant Acinetobacter infections: A review of the scientific evidence. J Antimicrob Chemother. 2008;62:45-55. http://dx.doi.org/10.1093/jac/ dkn165

125. Sader HS, Flamm RK, Jones RN. Tigecycline activity tested against antimicrobial resistant surveillance subsets of clinical bacteria collected worldwide (2011). Diagn Microbiol Infect Dis. 2013;76:217-21. http://dx.doi.org/10. 1016/j.diagmicrobio.2013.02.009

126. Pankey GA. Tigecycline. J Antimicrob Chemother. 2005; 56:470-8.

127. Brandon M, Dowzicky MJ. Antimicrobial susceptibility among Gram-positive organisms collected from pediatric patients globally between 2004 and 2011: Results from the Tigecycline Evaluation and Surveillance Trial. J Clin Microbiol. 2013;51:2371-8. http://dx.doi.org/10.1128/JCM. 00157-13

128. Garza-González E, Dowzicky MJ. Changes in Staphylococcus aureus susceptibility across Latin America between 2004 and 2010. Braz J Infect Dis. 2013;17:13-9. http://dx.doi.org/10.1016/j.bjid.2012.08.017

129. Martínez E, Alquichire C, Pérez C, Prada G, Rozo V, Larotta J. Comparación de la actividad in vitro de la tigeciclina contra microorganismos causantes de infección en pacientes hospitalizados en Colombia: estudio de evaluación y vigilancia de tigeciclina TEST. Infectio. 2007; 11:159-70.

130. Werner G, Gfrörer S, Fleige C, Witte W, Klare I. Tigecycline-resistant Enterococcus faecalis strain isolated from a German intensive care unit patient. J Antimicrob Chemother. 2008;61:1182-3. http://dx.doi.org/10.1093/jac/ dkn065

131. Cordina C, Hill R, Deshpande A, Hood J, Inkster T. Tigecycline-resistant Enterococcus faecalis associated with omeprazole use in a surgical patient. J Antimicrob Chemother. 2012;67:1806-7. http://dx.doi.org/10.1093/jac/ dks122

132. Steed ME, Rybak MJ. Ceftaroline: A new cephalosporin with activity against resistant gram-positive pathogens. Pharmacotherapy.2010;30:375-89. http://dx.doi.org/10.1592/ phco.30.4.375.

133. Saravolatz LD, Stein GE, Johnson LB. Ceftaroline: A novel cephalosporin with activity against methicillinresistant Staphylococcus aureus. Clin Infect Dis. 2011; 52:1156-63. http://dx.doi.org/10.1093/cid/cir147

134. File TM Jr, Wilcox MH, Stein GE. Summary of ceftaroline fosamil clinical trial studies and clinical safety. Clin Infect Dis 2012;55 S173-80. http://dx.doi.org/10.1093/cid/cis559.

135. Zhanel GG, Sniezek G, Schweizer F, Zelenitsky S, Lagacé-Wiens PR, Rubinstein E, et al. Ceftaroline: A novel broad-spectrum cephalosporin with activity against meticillin-resistant Staphylococcus aureus. Drugs. 2009; 69:809-31. http://dx.doi.org/10.2165/00003495-20096907000003

136. Farrell DJ, Castanheira M, Mendes RE, Sader HS, Jones RN. In vitro activity of ceftaroline against multidrugresistant Staphylococcus aureus and Streptococcus pneumoniae: A review of published studies and the AWARE Surveillance Program (2008-2010). Clin Infect Dis 2012;55:S206-14. http://dx.doi.org/10.1093/cid/cis563

137. Clark C, McGhee P, Appelbaum PC, Kosowska-Shick K. Multistep resistance development studies of ceftaroline in gram-positive and -negative bacteria. Antimicrob Agents Chemother. 2011;55:2344-51. http://dx.doi.org/10.1128/AAC. 01602-10

138. Murthy B, Schmitt-Hoffmann A. Pharmacokinetics and pharmacodynamics of ceftobiprole, an anti-MRSA cephalosporin with broad-spectrum activity. Clin Pharmacokinet. 2008;47:21-33. http://dx.doi.org/10.2165/00003088-20084 7010-00003

139. Chahine EB, Nornoo AO. Ceftobiprole: The first broadspectrum anti methicillin-resistant Staphylococcus aureus 
Beta-Lactam. J Exp Clin Med. 2011;3:9-16. http://dx.doi. org/10.1016/j.jecm.2010.12.007

140. Anderson SD, Gums JG. Ceftobiprole: An extendedspectrum anti-methicillin-resistant Staphylococcus aureus cephalosporin. Ann Pharmacother. 2008;42:806-16. http:// dx.doi.org/10.1345/aph.1L016

141. Jones RN, Deshpande LM, Mutnick AH, Biedenbach DJ. In vitro evaluation of BAL9141, a novel parenteral cephalosporin active against oxacillin-resistant staphylococci. J Antimicrob Chemother. 2002;50:915-32. http://dx. doi.org/10.1093/jac/dkf249
142. Banerjee R, Gretes M, Basuino L, Strynadka N, Chambers HF. In vitro selection and characterization of ceftobiprole-resistant methicillin-resistant Staphylococcus aureus. Antimicrob Agents Chemother. 2008;52:2089-96. http://dx.doi.org/10.1128/AAC.01403-07

143. Barton E, MacGowan A. Future treatment options for Gram-positive infections--looking ahead. Clin Microbiol Infect. 2009;15 S6:17-25. http://dx.doi.org/10.1111/j.14690691.2009.03055.x 